\title{
The relationship between spiritual health and hope in multiple sclerosis patients: A descriptive-correlational study
}

\author{
Zahra Ahmadian Niyazmand ${ }^{1}$, Abbass Abbasszadeh ${ }^{2}$, Fariba Borhani ${ }^{3}$, Reyhaneh Sefidkar ${ }^{4}$
}

\begin{abstract}
Background and Objectives: Spiritual health is the ultimate extremity of health which becomes the main objective of life by creating sense and meaning in life. In chronic disease such as Multiple Sclerosis, hope is one of the factors that can bring about positive consequences in order for the patient to cope with the disease consequences and improve his/ her ability to cope with the disease. In current study, the study of the role of hope in promotion of spiritual health is addressed. It is essential to study the relationship between spiritual health and hope in chronic patients due to the necessity of change in their lifestyle. Therefore, this study has been carried out with the objective of exploring the relationship between spiritual health and hope in MS patients in Iran.

Materials and Methods: This descriptive-correlational study was performed on 103 subjects admitted by Red Crescent Clinic in Tabriz, a metropolitan city in the north-west of Iran. They all suffered from Multiple Sclerosis. Paloutzian and Ellison's Questionnaire of Spiritual Health and Snyder's Questionnaire of Hope was utilized to collect the data. Data analysis was performed on the basis of Independent T-Test and Mann-Whitney's U-Test and correlation coefficient was calculated with the help of SPSS ver. 19.

Findings: Mean and standard deviation of total score of spiritual health $92.39 \pm 20.89$ and mean and standard deviation of total score of hope $39.98 \pm 7.97$ were obtained and the results indicated that there is a significant relationship between spiritual health and hope in the patients $(P<0.001$ and $r=0.538$ ) and no significant relationship between spiritual health and hope could be seen regarding any demographic variables. Also, there was no significant relationship between existential health and demographic variables. There was no significant relationship between religious health and demographic variables excluding education.

Conclusion: According to the results of this study, one can consider hope as a factor in relation with spiritual health that can have positive and useful effects on the improvement of MS patients. Therefore, hope promotion plans can be considered as effective in promoting spiritual health so as to care for the patients.
\end{abstract}

Keywords: multiple sclerosis, spiritual health, hope

\section{INTRODUCTION}

There is a strong relationship between spirituality and capability to adapt with the disease in chronic patients and spiritual and religious beliefs can cause reduction in pain level, social withdrawal and depression and increase in life satisfaction. Spiritual beliefs can be considered as an important factor in maintaining health, well-being and adaptation with the disease and sensation of spiritual well-being increases as the age and disease course increase (1). Hope is one of the main resources of adaptation capability for the chronic patients to survive and has impacts on the individual's personal attitudes, his / her health status and facilities in future (2). Multiple Sclerosis is a chronic disease which demyelinates central nervous system with the mediation of T-cells (3) which leaves undesirable effects on different dimensions of the patient's personal and family life. Multiple Sclerosis generally prevails during proliferous and

\footnotetext{
M.S. Student of Research Committee, School of Nursing and Midwifery, Shahid Beheshti University of Medical Sciences, Tehran, Iran.

2 Professor, School of Nursing and Midwifery, Medical Ethics and Law Research Center, Shahid Beheshti University of Medical Sciences, Tehran, Iran.

3 Associate Professor, Medical Ethics and Law Research Center, School of Nursing and Midwifery, Shahid Beheshti University of Mecdical Sciences, Tehran, Iran.

4 Ph.D. Student of Statistics, Faculty of Paramedicine, Shahid Beheshti University of Medical Sciences, Tehran, Iran.
}

Correspondence: Abbass Abbasszadeh

Professor, School of Nursing and Midwifery, Medical Ethics and Law Research Center, Shahid Beheshti University of Medical Sciences, Tehran, Iran.

E-mail: aabaszadeh@hotmail.com

Received: 8 Feb 2018, Accepted: 24 Apr 2018

(C) 2018 by the authors; licensee Modestum Ltd., UK. This article is an open access article distributed under the terms and conditions of the Creative Commons Attribution License (http://creativecommons.org/licenses/by/4.0/). 
productive years of life ranging 20-40 years of age (4). In addition to physical conditions and materialistic factors, high percentage of nervous and emotional problems (84.4\%) again diverts the attentions to the psychosomatic aspect of MS and the control of emotional affairs due to psychological-social problems. As the patients themselves expressed, these problems include desperation, feeling extremely sad and lonesome, bitter and sweet excitements, extreme depression, anger suppression and tolerating its somatic reactions like itching, high sensitivity, mental-emotional pressures, anxieties and worries, family problems and interpersonal and other mental-social problems (4). These patients usually confront a vast array of such negative feelings as anxiety, anger and depression, especially when the disease leads the patients' roles and their valuable activities to decline and their social relations to change and their previous activities to be rendered as difficult or even impossible (5). Studies have indicated that approximately 25 to 40 percent of the patients with MS suffer from anxiety (6). These conditions make the patient have undesirable feelings so that $\mathrm{s} / \mathrm{he}$ might think that there is no prospective future for her / him for the reason that most of the patients in this course of disease seek for meaning in their lives (7). Since there is no pharmaceutical therapy for MS, life expectancy and revitalization can enhance coping with the disease (8). Based on previously mentioned points about high prevalence of mental health problems in patients with MS, performing diagnostic sessions and mental-social therapies other than common pharmaceutical therapies is of high importance to alleviate its symptoms and improve the life quality of patients. Since this disease is considered to be one of the menacing factors to threat hope, it will be very important to target MS patients' hope via psychotherapy (9). Hope consists of the power to concentrate, attend, plan and target the objectives in life. Studies report that hope leads to the improvement of self-efficacy, self-esteem, spirituality promotion, social support and patient life quality enhancement (10).

There are several concepts about how to cope with problems and tensions resulting from disease one of which is spiritual health that causes integrity among other concepts and, in itself, it includes two dimensions: existential and religious. Religious health refers to the satisfaction resulting from establishing relation with a supreme power and existential health refers to the attempt to understand meaning and objectives in life (11). Spiritual health is one of the concepts which is put forth and developed thanks to the psychologists' global attention to and interest in the field of religion and spirituality. This has caused the fact that WHO might have recently wanted to define the human beings as a biological, mental, social and spiritual. Having faith in God and belief in one source of truth and one absolute and supreme power enhances the capability to tolerate frustrations and thereby contributes to the maintenance of physical and mental health and prevents from emergence of physical and mental disease and also furthers human hope for the future (12). When spiritual health is seriously endangered, the individual become stricken by mental disorders such as feeling lonesome, depression and losing sense and meaning in life. The patient whose spiritual health is revived can effectively adapt themselves with the disease and they can easily spend the last course of the disease. Thus, supporting the spiritual or religious resources and establishing a relationship with supreme power is fruitful in a way that it can help the patient improve his/ her life quality, reduce and control mental health disorders, enhance interpersonal relationship, reduce the severity of symptoms and positive medical results (13).

Evidence shows that spiritual health plays an important role in reinforcing the patient's capability to cope with the disease consequences. Study results by Vegharseyyedin et al (2014) indicated that in Iranian MS patients, spiritual health could drive the individual so as to control his/ her disease (8). MS patients experience various physical, mental and social consequences and their human dignity is threatened as well due to chronic MS. Gold et al (2005) introduce some psychological and social factors that put the MS patients under such pressures as mental preoccupations due to the disease, fear from death and worries from future, losing their jobs and concerns about providing treatment costs and so forth. Meanwhile, if the patient is helped with reviving miraculous power of hope, one can imagine how a bright window opens up for the patient's life full of pains, sufferings and fear (14). In his studies, Morgante (2000) also emphasized on the important role of hope in MS patients in reinforcing the personal ability to maintain independence (15).

Since technical interventions regarding life threats have not so far been responsive to the problems faced with incurable patients, attention to such strong parameters as spirituality and hope has been increasingly diverted in many societies (16). Some studies concerning the concept of spiritual health and hope have been separately performed in different patients, but few researches have assessed the potential relationship between these two factors. Concerning the importance of hope and spiritual health in promoting adaptability with chronic disease, including MS, performing studies in this field can help the patients prevent mental pressures by improving spiritual health and hope. Thus, this study was carried out with the aim of investigating the role of spiritual health and hope among MS patients admitted by Red Crescent Clinic in Tabriz, a metropolitan city in the north-west of Iran. 


\section{RESEARCH METHOD}

This is a cross-sectional descriptive-correlational study performed on MS patients admitted by Red Crescent Clinic in Tabriz, Iran, in 2016. Given the objectives of the research, sample size after preliminary sampling (sample size 20) was calculated using this formula:

$$
\begin{gathered}
\alpha=0.045 \\
1-\beta=0.9 \\
r=.34 \\
C=0.5 \ln [(1+r) /(1-r)] \\
N=\left[\left(Z_{\alpha}+Z_{\beta}\right) / C\right]^{2}+3
\end{gathered}
$$

Sample size was calculated as 89 , but minimum required sample size of 103 was obtained with the estimation of $15 \%$ fall-out. In this research, 103 subjects from among MS patients admitted by Red Crescent Clinic to receive special injections were selected for the study. They all qualified the research requirements. Research requirements included Muliple Sclerosis diagnosis by therapist doctor and the patient's ability to establish relations.

Data collection instruments consisted the questionnaire of demographic information, Paloutzian and Ellison's Questionnaire of Spiritual Health and Snyder's Questionnaire of Hope. In the questionnaire of demographic information such demographic information as age, gender, education, marital status, occupation, body part involved and medicine taken by the patients were meant to be questioned. Paloutzian and Ellison's Questionnaire of Spiritual Health was designed in 1983. It is a 20-item questionnaire with odd number items assessing religious health and even number items assessing existential health. The score for the spiritual health is the sum of the scores of these two subgroups which ranges 20-120. The choices offered range from 'I completely agree' to 'I completely disagree' according to Likert's 6item scale.

Snyder's Questionnaire of Hope was designed in 1991 and has 12 items. Its objective is to assess the level of individual's optimism and hopefulness in life. This questionnaire includes operant and strategy scale. Its scoring mechanism is based on Likert's five multiple-choice scales. The choice 'I completely disagree' is given the score value of 1 but this scoring is reverse about items 11, 7 and 3. Validity of this questionnaire is assessed in Iran several times. To examine its reliability, Cronbach's Alpha was calculated with 0.71 for Snyder's Questionnaire of Hope and 0.76 for the Questionnaire of Spiritual Health according to Likert's scale. Available sampling method was used to choose the samples. This research has ethical code of (IR.Sbmu.Research.Rec.1395.118.247422)95/4/28. The researcher submitted the letter of recommendation to the manager of Red Crescent Clinic. Having respected ethical and human considerations of research and explained the research to MS patients admitted to the research, she offered the questionnaire to them and assured them that their responses will be kept confidential and in return, she urged them to answer the questions honestly. Descriptive statistics methods such as frequency, percentage, mean and standard deviation were used to analyze the data. Pearson's Correlation Test was used to determine the relationship between Hope and Spiritual Health. Data analysis was performed on SPSS ver. 19.

\section{FINDINGS}

In this research 103 subjects with MS were studied from whom 76.7 percent were female and 60.2 percent were single and 68 percent were either employed or university students. The patients were 44.7 percent normal concerning the body part affected. Most of the patients, 59.2 percent, had university degrees: B.A./ B.S. or M.A./ M.S. The mean and standard deviation of the age of the people referring to the Red Crescent Clinic were 32.65 and 7.45, respectively; and mean and standard deviation for the disease course were 5.15 and 3.25, respectively (Table 1). In Table 1, demographic characteristics of the MS patients are presented. 
Table 1: Demographic Characteristics of the MS patients

\begin{tabular}{|c|c|c|}
\hline Variable & Frequency & percent \\
\hline \multicolumn{3}{|c|}{ Age } \\
\hline Male & 79 & 76.7 \\
\hline Female & 24 & 23.3 \\
\hline \multicolumn{3}{|c|}{ Marital Status } \\
\hline Single & 62 & 60.2 \\
\hline Married & 41 & 39.8 \\
\hline \multicolumn{3}{|c|}{ Occupation } \\
\hline Employed/ Student & 70 & 68 \\
\hline Housewife & 33 & 32 \\
\hline \multicolumn{3}{|c|}{ Income } \\
\hline inadequate for living & 10 & 9.7 \\
\hline adequate for living & 91 & 88.3 \\
\hline more than adequate & 2 & 1.9 \\
\hline \multicolumn{3}{|c|}{ Body part affected } \\
\hline Eye & 16 & 15.5 \\
\hline leg/ foot & 18 & 17.5 \\
\hline arm/ hand & 5 & 4.9 \\
\hline None & 46 & 44.7 \\
\hline \multicolumn{3}{|c|}{ Education } \\
\hline Diploma/ undergraduate & 42 & 40.8 \\
\hline $\begin{array}{c}\text { Graduate (B.A./ B.S.)/ } \\
\text { Postgraduate (M.A./ M.S.) }\end{array}$ & 61 & 59.2 \\
\hline
\end{tabular}

Table 2: Mean and SD of spiritual health and its dimensions (religious health and existential health) as well as hope in MS patients

\begin{tabular}{cccc}
\hline Variable & Mean & SD \\
\hline Spiritual Health & 92.39 & 20.86 & \\
\hline Religious Health & 49.35 & 8.82 & \\
\hline Existential Health & 43.02 & 15.60 & \\
\hline Hope & 39.98 & 7.97 & \\
\hline
\end{tabular}

Table 3: Relationship between spiritual health and hope in MS patients under study

\begin{tabular}{ccc}
\hline Variable & Pearson's correlation coefficient & SD \\
\hline spiritual health and hope & 0.538 & P $<0.001$
\end{tabular}

The results showed that mean and standard deviation of total score of hope were 39.98 and 7.97 and mean and standard deviation of total score of spiritual health were 92.39 and 20.86, respectively. Statistical results in Table 2 indicate mean and standard deviation of spiritual health and its dimensions, i.e. existential health and religious health.

Pearson's Correlation Test showed that there is a significant relationship between spiritual health and hope in MS patients under study $(r=0.538$ and $P<0.001)$ (Table 3).

Mann-Whitney's U-Test showed significant relationship of spiritual health, existential health and hope with none of the demographic variables like age, marital status, occupation, income, body part affected and disease course. Also, this test showed that there is no significant relationship between religious health and variables excluding education $(P=$ 0.035).

\section{DISCUSSION}

This research is performed with the objective of exploring the relationship between spiritual health and hope among patients with Multiple Sclerosis. The results showed that there is a positive and significant relationship between hope and spiritual health. Given the fact that this disease prevails in sensitive years of life, these patients confront various difficulties including educational problems, life and marriage problems and occupational problems. Therefore it is highly important that there should be hope in life and some ways to enhance hope among these patients. Some evidence is indicative of the fact that counselling with spirituality perspective can promote hope among patients. Some studies carried out in Western countries have also indicated the role of spiritual health in coping with the diseases. For instance, Brook and Matson came to the conclusion that spiritual beliefs and faith of individuals can have positive impacts on the capability to cope with MS (17). Concerning determining the level of spiritual health among the patients with Multiple 
Sclerosis, the results of current study show that the mean and standard deviation of total score of spiritual health are 92.39 and 20.86, respectively, and these are higher than average value. Also, the results showed that there is no significant relationship between spiritual health and demographic variables like gender, occupation, education, marital status as well as age and course of disease. Positive relationship between spiritual health and hope was logical and expectable to a greater extent. Since Iranian society is a community with Islamic beliefs and teachings and spirituality is rooted in the lives of the nation, therefore, such a research result was not away from expectation. According to Islamic beliefs and teachings, remembering god pacifies the hearts and this pacification in life is one of the most important variables of life expectancy (hope). Thus, the existence of positive and significant relationship between Trust in God, hence, spiritual health, and life expectancy seems natural in this research (18). From the other hand, reliance on spirituality is a positive, pacifying and pleasing construct and it is totally obvious that emphasis on spirituality will contribute to public health of human beings (19). Religious beliefs during disease course becomes of more importance than any other time and helps the patient accept the disease more readily. Also, it helps him/ her to understand the undesirable life events, especially painful and distressful ones and thereby, to appreciate confidence and satisfaction in his soul and mind (20). Islamic psychology considers remembering God as a way to essentially cure and treat mental disorders like worries and anxiety because in ups and downs of the life and in confrontation with pains and sufferings, this is the memory of God that pacifies the hearts and souls (5). It is accounted that worshipping God can help the patients with chronic disease adapt much more easily (21).

In this research, mean and standard deviation of existential health are 43.02 and 15.60. Based on the results, there are no significant relationships between existential health and none of the demographic variables and also with age and disease course. Spiritual health is something beyond feeling religious and mainly manifested in the form of having relationship with God. From the other hand, behaviours like worshipping, pilgriming and trusting in God increases intrinsic pacification within individuals via creating hope and promoting positive perspectives (11).

Mean and standard deviation of religious health are 49.35 and 8.82 , respectively, given the research results, the relationship of religious health with none of the variables like gender, occupation, marital status, excluding education, is not significant and no significant relationship was shown between variables like age of patient and disease course and religious health. Religious beliefs and teachings can lead the individuals towards perfection and growth, hence, healthy mind. Faith in God or appreciation of divine aspects of life can create such a potentiality in individuals that the emergence of stressful conditions threatening the mental health can be removed and can provide the background for the development of optimism in the individuals (19).

The results of this study showed that only did the level of education have significant relationship with religious health so that this level of religious health is much more in the individuals holding diploma or undergraduate degrees than in the ones with graduate or postgraduate degrees. It seems that as the university degree advances, the level of religious health decreases and this could be for the reason that as education and university degree holding advances up, the relationship with God and extent of individuals' beliefs become limited. So the obtained result is indicative of the fact that in the universities of our Islamic country, we confront with the reduction of these beliefs, hence, reduction of religious health among the patients holding higher university degrees instead of creating a background for the promotion of beliefs which are cherished and sustained in families and brought onto society and university. Most of the people experience hopelessness and mistrust in their God after having faced with the problems and illnesses, especially the incurable one. Therefore, further research on the fields such as 'the impacts of university education on consolidation of religious beliefs' becomes of necessity.

In this research, mean and standard deviation of hope among MS patients were 39.98 and 7.97, respectively. Meanwhile, according to research results, there was no significant relationship between the score of hope and demographic variables like gender, occupation, education, marital status as well as variables of age and disease course. It is likely that since most of the patients' age ranged between 20 and 40 and most of them had some ambitions about their occupation, education, marriage and successes in their lives, total scores of hope soared up. The individuals with more hope and optimism also had higher self-esteem and more commitment in activities leading to better sanitation and health. It becomes obvious that these people take examples and pursuit their objectives of their prospective future instead of concentrating on undesirable life events (22). Despite the importance of the role of hope in mental and physical health, there had been no much attention to it in the past times. But in new movement of Positive Psychology, special attention is given to the issues of hope. It is urgently necessary that hope be taken seriously regarding chronic disease. 


\section{FINAL CONCLUSION}

Given that there is a relationship between hope and spiritual health among the patients with Multiple Sclerosis according to the results of current study and owing to the fact that today the role of psychological treatment of MS patients are less often addressed and also bearing in mind that application and implications of psychological interventions can be a new leap forward in improving the conditions for these patients, attention of specialists and caregivers of these patients, including nurses, and also the frequent application of psychological therapies like hope therapy besides other medical therapy can be a new step to eliminate the symptoms and improve the life quality of the patients.

\section{RESEARCH CONSTRAINTS}

Since the research sample was from the patients admitted only to Red Crescent Clinic in Tabriz, Iran, and there was no more access to all the MS patients in Tabriz, therefore, the generalizability of the findings should be performed with much caution. It is suggest to perform this research again in wider range and extent of patient samples.

\section{REFERENCES}

1. Büssing A, Matthiessen PF, Ostermann T. Engagement of patients in religious and spiritual practices: confirmatory results with the SpREUK-P 1.1 questionnaire as a tool of quality of life research. Health and Quality of Life outcomes. 2005;3(1):53. https://doi.org/10.1186/1477-7525-3-53

2. Ghezelseflo M, Esbati M. Effectiveness of Hope-oriented Group Therapy on Improving Quality of Life in HIV+ Male Patients. Procedia-Social and Behavioral Sciences. 2013;84:534-7. https://doi.org/10.1016/j.sbspro.2013.06.599

3. Pekmezovic TD, Tepavcevic DBK, Mesaros ST, Basuroski IBD, Stojsavljevic NS, Drulovic JS. Food and dietary patterns and multiple sclerosis: a case-control study in Belgrade (Serbia). Italian Journal of Public Health. 2012;6(1).

4. Zandipour T. MS patients' attitude toward the quality of their life and counseling and psychology services. 2009.

5. Hojjati H. Compare two methods of pray and mentioning on life expectancy i patients hospitalization in CCU Ward Social Security Golestan Hospitals in 1393. Complementary Medicine Journal of faculty of Nursing \& Midwifery. 2016;6(1):1384-94.

6. Esmonde L, Long AF. Complementary therapy use by persons with multiple sclerosis: benefits and research priorities. Complementary Therapies in Clinical Practice. 2008;14(3):176-84. https://doi.org/10.1016/j.ctcp.2008.03.001

7. Moghimian M, Salmani F. The study of correlation between spiritual well-being and hope in cancer patients referring to Seyyedo Shohada Training-Therapy center of Isfahan University of medical sciences, 2010, Isfahan, Iran. 2012.

8. Zarei B, Vagharseyyedin SA, Gorganie E. Relationship between Spiritual Well-Being and Self-Management among Iranian People with Multiple Sclerosis. Jundishapur Journal of Chronic Disease Care. 2015;4(4).

9. Rasouli M, Bahramian J, Zahrakar K. The effect of hope therapy on quality of life in multiple sclerosis patients. 2014.

10. Maslakpak M, Ahmadi F, Anoosheh M. Spiritual beliefs and quality of life: A qualitative research about diabetic adolescent girls' perception. Koomesh. 2011;12(2):144-51.

11. Rezaieshahsavarloo Z, Taghadosi M, Mousavi, Lotfi M, Harati K. The Relationship between spiritual well-being \& religious attitudes with life satisfaction in elderly cancer patients. 2016.

12. Yang K-P, Mao X-Y. A study of nurses' spiritual intelligence: A cross-sectional questionnaire survey. International journal of nursing studies. 2007;44(6):999-1010. https://doi.org/10.1016/j.jpurstu.2006.03.004

13. Momeni T, Musarezaie A, Karimian J, Ebrahimi A, et al. The relationship between spiritual well-being and depression in Iranian breast cancer patients. Health Information Management. 2012(0):524-

14. Gold SM, Mohr DC, Huitinga I, Flachenecker P, Sternberg EM, Heesen C. The role of stress-response systems for the pathogenesis and progression of MS. Trends in immunology. 2005;26(12):644-52. https://doi.org/10.1016/j.it.2005.09.010

15. Morgante L. Hope in multiple sclerosis: a nursing perspective. International Journal of MS Care. 2000;2(2):9-15. https://doi.org/10.7224/1537-2073-2.2.9 
16. Shahhoseini S, Borhani F, Shoorideh FA, Kavousi A, Bagheri H, Almasi-Hashiani A. Different Sources of DignityRelated Distress in Women Receiving Chemotherapy for Breast Cancer. Asian Pacific journal of cancer prevention: APJCP. 2017;18(11):2953-8.

17. Sharifi S, Borhani $F$, Abbaszadeh A. Factors affecting dignity of patients with multiple sclerosis. Scandinavian journal of caring sciences. 2016;30(4):731-40. https://doi.org/10.1111/scs.12299

18. Hassanzadeh R, Miriyan SA, Lezgi F. Studying the relationship between the trust in God and the quality of life and life expectancy Of Teachers of high schools in Teaching and Education center, first area of Sari City. Islam and Health Journal. 2014;1(2):15-21.

19. Ghahremani N, Nadi MA. Relationship between religious/spiritual components, mental health and hope for the future in hospital staff of Shiraz public hospitals. Iran Journal of Nursing. 2012;25(79):1-11.

20. Borhani F, Abbaszadeh A, Moosavi S. Status of human dignity of adult patients admitted to hospitals of Tehran. Journal of medical ethics and history of medicine. 2014;7.

21. Sajjadi M, Rassouli M, Abbaszadeh A, Majd HA, Zendehdel K. Psychometric properties of the Persian version of the Mishel's Uncertainty in IIIness Scale in Patients with Cancer. European Journal of Oncology Nursing. 2014;18(1):52-7. https://doi.org/10.1016/j.ejon.2013.09.006

22. Daryabygi R, Abdolmohammadi L, Alimohammadi N, Gazavi Z. The effect of group hope-therapy program on the improvement of life in burnt patient of Isfahan-Imam Mousa Kazem hospital: Clinicaltrial study. 2016.

$\diamond \diamond \diamond \diamond \diamond \diamond \diamond$

http://www.ejgm.co.uk 